\title{
DEMOCRACY AND THE COVID-19 PANDEMIC. A CROSS- COUNTRY PERSPECTIVE WITHIN CULTURAL CONTEXT
}

\author{
Monica Violeta Achim* \\ Babeș-Bolyai University, Cluj-Napoca, Romania \\ Viorela Ligia Văidean \\ Babeș-Bolyai University, Cluj-Napoca, Romania \\ Sorin Nicolae Borlea \\ Babeș-Bolyai University, Cluj-Napoca, Romania, University of Oradea, Romania, \\ West Vasile Goldis University, Arad, Romania \\ Decebal Remus Florescu \\ Babeș-Bolyai University, Cluj-Napoca, Romania \\ Neli Muntean \\ Technical University of Moldova, Chișinău, Republic of Moldova
}

\begin{abstract}
Our paper investigates the influence of democracy upon the spread of COVID-19. For the purpose of our study we use a sample consisting of 185 worldwide countries affected by the spread of the new coronavirus disease (54 high income and 131 low income countries). First, we find that in high income countries, higher levels of democracy reduce the spread of COVID-19 while in the low income countries its influence is exactly the opposite. Second, we find clear evidence that three dimensions of culture (individualism versus collectivism, uncertainty avoidance and masculinity versus femininity) influence people's behaviour in relation with the spread of COVID-19 in a large manner. This study's addressability is wide, from regular people to top policymakers, through their common goal of limiting this pandemic and all the negative effects it brings along. Our findings are important as their policy implications suggest that democracies perform badly for the poorest people and what can be done to improve their record.
\end{abstract}

Keywords: Democracy, COVID-19, Culture, High Income, Low Income.

Received: 27 August 2020

Accepted: 10 May 2021

https://doi.org/10.33736/ijbs.3734.2021

\section{INTRODUCTION}

The present paper investigates how the democratic rights of citizens affect the spread of Coronavirus Disease 2019 (COVID-19), an ongoing pandemic crisis which creates a big worldwide chaos. There are numerous debates and studies that investigate the role expressed by democracy upon public healthcare, trying to answer the question: Does democracy help or hinder

- Corresponding author: Faculty of Economics and Business Administration, Babeș-Bolyai University, Cluj-Napoca 400591, Romania; Address: Theodor Mihali no. 58-60, ZIP code 400591; Tel: +040 0741194473. Email: monica.achim@ econ.ubbcluj.ro 
the physical health of the population? (Ruger, 2005; Gerring et al., 2012; Bollyky et al., 2019; Kavanagh, 2020). This question has gained a tremendous importance in the current COVID-19 pandemic. Still, according to Norrlöf (2020), COVID-19 pandemic related researches within a still evolving crisis represent first attempts of social scientific assessments and are rather limited. Norrlöf (2020) finds that liberal democracies have higher case fatality rates than other regime types.

Moreover, researchers have tried to assess the impact and emerging effects of a wide palette of elements upon the evolution of the COVID-19 pandemic, ranging from social health determinants (Ataguba \& Ataguba, 2020) to globalisation (Zimmermann et al., 2020), governance (Gaskell \& Stoker, 2020), business activities (Achim et al. 2021, Mirza et al., 2020), population mobility (Gondauri \& Batiashvili, 2020), culture (Jovančević \& Milićević, 2020) and many others. Nevertheless, even the impact of the pandemic upon several dimensions of our lives, such as governing forms (Rapeli \& Saikkonen, 2020; Afsahi et al., 2020), has started to be empirically assessed. All these research directions are highly motivated by the current pandemic context, in order to be able to draw proper reform directions and adjust the policies, to the best of our benefit as individuals and nations.

However, to the best of our knowledge, there still are few studies in the literature which analyse the relationship between democracy and the spread of COVID-19 and this is the main original value of our research. A second element of originality of our work refers to the fact that the estimations are conducted on two groups of countries, as they greatly depend on their level of development (high or low income countries). Third, another element of originality relates to the fact that the heritage culture is taken into account in our analysis as being a factor which determines people's behaviour towards accepting the rules imposed by governments in the fight against the spread of COVID-19 (Hofstede, 2011).

We find clear evidence that high democracies correlate with the spread of COVID-19 but the results significantly differ between these two subgroups of countries. More exactly, in high income countries, higher levels of democracy reduce the spread of COVID-19 while in low income countries, its influence is opposite. In addition, three dimensions of culture, i.e. individualism versus collectivism, uncertainty avoidance and masculinity versus femininity, highly influence the behaviour in relation with the spread of COVID-19.

Second, the cultural heritage of each nation also contributes to these results. Thus, we find clear evidence that culture has a significant influence on the spread of COVID-19. As such, a more individualistic society is associated with a larger spread of COVID-19, in a context of high demands for freedom. In addition, uncertainty avoidance and masculinity versus femininity highly influence the behaviour of nations in relation with the proxies of COVID-19 for the analysed samples. Our findings are important as the related policy implications support the idea that democracies perform badly for poorer people and their record has to be somehow improved.

The remainder of the paper is organized as follows: Section 2 reveals the literature review in the field of the relationship between the level of democracy and the managerial response to COVID19 disease. Section 3 describes the applied methodology and the data. Section 4 presents the results of our analysis, presented as main results and robustness checks. Section 5 discusses our main empirical findings. Section 6 offers our conclusions and summarizes the findings, with a brief discussion on policy implications, limitations, and avenues for future research. 


\section{LITERATURE REVIEW}

There are several strands within the specialized literature investigating the role of democracy upon population health and finding results which may differ due to various determinant factors, such as:

a) the way of measuring democracy as: "stock" of democracy, meaning a long tradition of democratic governance (Gerring et al., 2012; Annaka \& Higashijima, 2017; Gettysburg Foundation, 2020) or democracy at a certain moment of time (Kudamatsu, 2012; Liotti et al., 2018); the extent of freedom of a particular country (Franco et al., 2004; Wigley et al., 2020);

b) the measuring way of population health, such as: infant mortality rate (Kudamatsu, 2012; Franco et al., 2004; Safaei, 2006; Wigley \& Akkoyunlu-Wigley, 2017; Annaka \& Higashijima, 2017); adult mortality rate (Safaei, 2006)); quality of life (Stroup, 2006); life expectancy (Franco et al., 2004; Safaei, 2006); treatment of HIV/AIDS (Justesen, 2012); human development index (Liotti et al., 2018); non-communicable diseases (Bollyky et al., 2019; Allen et al., 2020; Wigley et al., 2020); communicable diseases such as Covid19 (Kavanagh, 2020; Berengaut, 2020);

c) the sample in which the analysis is conducted, because the results may differ by levels of country development (Achim et al. 2020; Ramos, 2014).

Furthermore, a large strand of studies highlights the positive role of democracy in improving health outcomes. As such, Akerman et al. (2019) points out the fact that democracy creates incentives for health promotion. Democratic societies tend to have better healthcare and human development indexes as compared to other countries (Bollyky et al., 2019). This is justified by the fact that competing elections, well-established life equilibria and press freedom encourage political leaders to be responsible for their citizens (Annaka \& Higashijima, 2017; Przeworski et al., 2000). In this view, the study of Gerring et al. (2012) highlights that it is the stock of democracy that reduces infant mortality rates rather than the level of democracy. Similar results on a long-run effect of democracy on reducing infant mortality are obtained by Annaka and Higashijima (2017) using a newly collected panel data of infant mortalities covering the time span from 1800 to 2015. Also related to infant mortality, for the poor African countries, Kudamatsu (2012) finds that an increase in the level of democracy reduces infant mortality rates. Similar results are obtained by Wigley and Akkoyunlu-Wigley (2017) who find that democratic governments are likely to reduce child mortality among low income families.

Similarly, regarding health outcomes such as life expectancy and maternal and infant mortality, the study conducted by Franco et al. (2004) finds that democracy, political rights, and civil liberties are politically modifiable variables that are associated with these health statuses. In the same view, working on a sample of 18 former Socialist countries for the 1990-2014 period, the study of Liotti et al. (2018) also finds a positive influence of democracy upon the human development index.

Fewer studies focus on studying the relationship between democracy and disease management. Thus, Justesen (2012) finds that democracy on average increases the access to HIV / AIDS treatment. Similarly, Bollyky et al. (2019) finds a positive association between democracy on the one hand and cardiovascular diseases and transport injuries on the other.

Another strand of studies validates reduced influences of democracy upon health outcomes (Allen et al., 2020; Stroup, 2006) or having effects conditioned by other factors (Annaka \& Higashijima, 
2017; Gerring et al., 2012; Ramos, 2014; Miller, 2015). Some results sustain that democracy doesn't reduce infant mortality rate (Ross, 2006) or it does not interfere with the quality of life (Stroup, 2006). As such, Stroup (2006) analyses the relationship between democracy and quality of life considering the interaction between democracy and economic freedom. He finds that democracy has a smaller positive influence that disappears for many welfare measures in countries with more economic freedoms. Some other studies approve that certain conditions have to be fulfilled in order for democracy to produce positive effects upon health outcomes (Annaka \& Higashijima, 2017). Among these conditions, researchers mention: a long tradition of democratic governance (Gerring et al., 2012), a reduced economic development (Ramos, 2014) or strong competing parties at elections (Miller, 2015; Gerring et al., 2016). A very recent study of Allen et al. (2020) finds weak evidence for a positive association between democracy and the implementation of polices to reduce the premature noncommunicable disease mortality. However, their research is immediately countered by the study of Wigley et al. (2020) who finds a positive association between democracy and population health outcomes on non-communicable diseases.

The worldwide spread COVID-19 pandemic has determined a new wave of research materials on its determinants. Jovančević and Milićević (2020) check the role of optimism, trust, sources of information, conspiracy theory and fear in COVID-19 related behaviours, on a sample of 412 individuals from Serbia and Latin-America. Their April 2020 survey, points out the fact that the fear of food shortage is the most pronounced fear, and the more informed people are, regardless of the information sources, the more they fear. Their paper also supports the idea that cultural differences between the two subsamples are responsible for the respect shown to publicly recommended behaviours in the COVID-19 pandemic. Then, Ataguba and Ataguba (2020) place effective communication, especially crisis and risk communication, at the very centre of importance of social determinants of health for the COVID-19 pandemic, especially in developing countries with fragile healthcare systems. Effective crisis and risk communication builds trust, credibility, honesty, transparency and accountability, also emphasizing the countries' peculiarities in terms of regional, cultural, linguistic and ethnic diversity. Moreover, Zimmermann et al. (2020) capture the initial impact of the pandemic in terms of transmission speed from China to another country, infection rate (number of cases divided to the population) and the case fatality rate, as a function of the degree of economic globalization, measured through the KOF indices, and various controls. Their empirical findings validate the fact that the more globalized countries are affected by the pandemic faster and with a larger impact.

Closer to our research interest is the paper of Gaskell and Stoker (2020), who blame the varying degrees of success in managing the worldwide pandemic on the strengths and weaknesses of different governance arrangements leveraged to tackle the crisis. Then, using inferential statistics techniques and the case fatality rates, as well as the V-Dem liberal democracy scores, Norrlöf (2020) finds that liberal democracies have higher case fatality rates than other regime types. On the other hand, some recent papers test the potential short run and long run effects of this pandemic upon democracies. As such, Rapeli and Saikkonen (2020) expect the current pandemic not to have grave long-term effects on established democracies, considering that even in pre-pandemic times, when established democracies have been tested, they have endured. On the other hand, in the short term, the repercussions of the pandemic can aggravate the situation in countries that are already experiencing democratic erosion. However, Rapeli and Saikkonen (2020) estimate that the longterm economic effects of the pandemic may be more detrimental to non-democratic countries. An 
editorial worth mentioning is that of Afsahi et al. (2020), who depict some lessons taught by the evolution of this pandemic, showing the impact of the pandemic upon contemporary democracies.

One lesson is that COVID-19 has had corrosive effects on already endangered democratic institutions. Coming with clear examples from Central and Eastern Europe (Hungary, Poland) and Latin America (El Salvador, Bolivia, Chile), Afsahi et al. (2020) argue that this pandemic accelerates democratic erosion, the latter also being addressed in United Nations Development Programme (2004). Still, their future perspectives are somehow encouraging, considering that democracies would come out of this pandemic better than other government forms.

All in all, democracy is based on human rights standards and principles. Human rights are sometimes misunderstood as a system in which the individual enjoys complete freedom, so the drastic isolation rules imposed by some governments in countries affected by the COVID-19 pandemic have been more or less respected by the population of these countries. In addition, high income countries generally experience long-term democracies with an inherited culture of accepting the imposed rules compared to the low income countries, which experience relatively new democracies and a specific culture of asking for new freedoms. This may influence the impact of democracy and the way rules are accepted by the nations from each of the two subgroups of countries.

Based on the aforementioned, we state the following research questions:

Research question 1: How does democracy influence the spread of COVID-19?

Research question 2. How does the impact of democracy upon the spread of COVID-19 differ among high income and low-income countries?

\section{METHODOLOGY AND DATA}

The dependent variable COVID-19's spread is at the centre of our research. To measure the COVID-19's spread we use two main indicators: a) Cases, representing the number of COVID-19 confirmed cases per 1 million population; b) Deaths, representing the confirmed number of COVID-19 deaths per 1 million population. For this purpose, we use the most recent officially reported governmental data (July 112020 ), provided by national governments of countries through the Worldometers (2020) official data collection platform.

The independent variable is Democracy.

Considering the conceptualization of Abraham Lincoln (1863), democracy means "governing the people, by the people, for the people". Western states combine the concept of liberalism and the rule of law to develop constitutional liberalism, which holds individual rights, property rights, freedom of religion, freedom of speech, equality, separation of church and state (Zakaria, 1997). In order to measure the level of democracy from a country, the following measurements are used:

a) Democracy index, based on 60 indicators grouped in five different categories, measuring five dimensions of democracy such as Electoral process and pluralism, Functioning of government, Political participation, Political culture and Civil liberties. According to this score each country may be categorized as belonging to one of the 
following types of regimes: full democracies, flawed democracies, hybrid regimes and authoritarian regimes. Democracy index ranges between 1 (very low democracy) to 10 (very high democracy). This index is provided annually starting from 2006 by The Economist Intelligence Unit. For our purpose, the most recent report of The Economist Intelligence Unit (2019) is used.

b) Electoral Democracy Index, Liberal Democracy Index and Participatory Democracy Index. All the three indicators range between 0 (very low democracy) and 1 (very high democracy). These indexes are provided by V-Dem Institute (2020).

Our control variables include Culture, Urbanization, Unemployment and Pollution.

Our paper investigates the influence of democracy upon the spread of COVID-19. Following the literature research we have to control for several variables which are used in previous studies as determinants for population health, namely: Culture (Napier et al., 2014; Albert \& Trommsdorff, 2014; Achim et al., 2020); Urbanization (Dutta \& Gupta, 2019; Stearns et al., 2000); Unemployment (Maiti \& Awasthi 2020; Tefft, 2011) and Pollution (Landrigan et al., 2017; Thomas \& Zelikoff, 1999; Yue et al., 2018; World Health Organization, 2020). Regarding Culture, Lancet Commission is among the first ones to have documented that the effects of cultural systems of values upon health outcomes are huge, within and across cultures (Napier et al., 2014). Culture produces changes in human behaviour and therefore life expectancy can be affected (Albert \& Trommsdorff, 2014).

In our paper, culture relies on Hofstede's cultural model (Hofstede Insights, 2020 and Hofstede, 2011) comprising the following six dimensions: Power distance (PD), Individualism versus collectivism (IDV), Masculinity versus Femininity (MAS), Uncertainty avoidance (UAI), Longterm orientation (LTO), Indulgence and restraint (IND), keeping the significant ones through the backwards estimation technique. The studies conducted by Hofstede are beneficial for understanding the cultural dynamics of nations (Javidan et al., 2006). Urbanization (determined as the percentage of total population living in urban areas) brings along more knowledge and openness towards a healthy lifestyle of the population and an improved access to healthcare services (Dutta \& Gupta, 2019).

Then, increased Unemployment generates additional social tension, having a negative impact upon the wellbeing level of nations (Maiti \& Awasthi, 2020). A higher level of unemployment rates increases the number of attempts of looking for anti-depression solutions (Tefft, 2011) and it has a significantly positive influence on suicides (Breuer, 2015). Regarding Pollution, many studies reveal a strong relationship between pollution and health, especially for respiratory diseases. The large study of Landrigan et al. (2017) within the Lancet Commission finds that pollution is the largest environmental cause of diseases and premature deaths in the world today. Pollution kills 7 million people every year (World Health Organization, 2020) while for 2015 this number is 9 million representing premature deaths caused by pollution (about $16 \%$ of all deaths worldwide) (Landrigan et al., 2017). Pollution is mainly related to respiratory diseases (Yue et al., 2018) and it increases the risk for pulmonary infections (Thomas \& Zelikoff, 1999). Actually, worldwide, nine out of ten people now breather polluted air (World Health Organization 2020). The study of Yue et al. (2018) finds that the number of respiratory diseases is significantly higher under cold and hot uncomfortable levels than within comfort levels. In addition to that, the air components 
$\mathrm{PM}_{2.5}, \mathrm{SO}_{2}$, and $\mathrm{NO}_{2}$ have immediate effects upon respiratory diseases, while the $\mathrm{CO}_{2}$ has the highest risk if lagged for four days.

Our sample consists of 185 worldwide countries (54 high income countries and 131 low income countries) affected by the spread of the new coronavirus disease and the paper uses extremely recent data available for all the considered variables (on July 11, 2020) to the very date of our research. A synthesis of the variables and their proxies is presented in Appendix 1.

The baseline model specification has the following form:

$$
\operatorname{COVID-19}_{\mathrm{i}}=\boldsymbol{\beta}_{\mathbf{0}}+\boldsymbol{\beta}_{1} \text { Democracy }_{\mathrm{i}}+\boldsymbol{\beta}_{2} \text { Controls }_{\mathrm{i}}+\boldsymbol{\varepsilon}_{\mathrm{i}}(\mathrm{Eq} 1), \text { where }
$$

COVID-19 represents the quantification of COVID-19 proxies (Cases/1 million people, Deaths/1 million people, Tests/1 million people and Case fatality rate-CFR in percentages as described in Table $\mathrm{i}$, logged values for normality reasons) in countries $i$ at the date of our study; Democracy is the independent variable described before; Controls represents the vector of control variables presented before (Culture, Urbanization, Unemployment and the logged value of $\mathrm{CO}_{2}$ emissions). This research paper econometrically models unbalanced data for the entire sample of 185 COVID19 affected countries. Data are cross-sectional and the methodology applied uses the Ordinary Least Squares (OLS) technique. Log-linear regressions are used and a combinatorial approach estimation technique: forward estimations for building up Eq 1 and backwards estimations for reducing the number of cultural dimensions to the only ones that are significant.

For a more detailed approach of the COVID-19 pandemic variables, we further estimate Eq 1 for two subsamples of high income and low-income countries, as detailed in Appendix 2.

Table 1 includes, besides the summary statistics for the entire sample (_all), the summary statistics of the variables for the two subsamples of high income (_HI) and low-income countries (_LI). Table 2 provides the correlation matrix between these key variables.

Table 1: Descriptive statistics

\begin{tabular}{lrrrrr}
\hline \hline Variables & Obs & \multicolumn{1}{c}{ Mean } & Std. Dev. & Min & Max \\
\hline Dependent variable: COVID-19 & & & & & \\
$\quad$ Cases_all & 176 & 2136.83 & 3995.42 & 1 & 36729 \\
Cases_HI & 53 & 4177.094 & 6151.595 & 19 & 36729 \\
Cases_LI & 123 & 1257.691 & 2044.814 & 1 & 10593 \\
$\quad$ Deaths_all & 161 & 70.9484 & 136.8584 & 0 & 844 \\
Deaths_HI & 52 & 140.7154 & 204.2531 & 0.3 & 844 \\
Deaths_LI & 109 & 37.6651 & 67.7204 & 0 & 349 \\
$\quad$ Tests_all & 160 & 46794.55 & 70327.29 & 4 & 437346 \\
Tests_HI & 53 & 101560.1 & 95745.93 & 3284 & 437346 \\
Tests_LI & 107 & 19667.68 & 26063.23 & 4 & 152191 \\
$\quad$ Case fatality rate_all & 176 & 3.1436 & 3.5887 & 0 & 26.2779 \\
Case fatality rate_HI & 53 & 4.3306 & 4.2923 & 0 & 17.5716 \\
Case fatality rate_LI & 123 & 2.6322 & 3.1217 & 0 & 26.2779 \\
Independent variables: & & & & &
\end{tabular}


Democracy Index_all

Democracy Index_HI

Democracy Index_LI

Electoral Democracy Index_all

Electoral Democracy Index_HI

Electoral Democracy Index_LI

Liberal Democracy Index_all

Liberal Democracy Index_HI

Liberal Democracy Index_LI

Participatory Democracy Index_all

Participatory Democracy Index_HI

Participatory Democracy Index_LI

Control variables:

\section{Culture}

$$
\begin{aligned}
& \text { PD_all } \\
& \text { PD_HI } \\
& \text { PD_LI } \\
& \text { IDV_all } \\
& \text { IDV_HI } \\
& \text { IDV_LI } \\
& \text { MAS_all } \\
& \text { MAS_HI } \\
& \text { MAS_LI } \\
& \text { UAI_all } \\
& \text { UAI_HI } \\
& \text { UAI_LI } \\
& \text { LTO_all } \\
& \text { LTO_HI } \\
& \text { LTO_LI } \\
& \text { IND_all } \\
& \text { IND_HI } \\
& \text { IND_LI }
\end{aligned}
$$

Urbanization_all

Urbanization_HI

Urbanization_LI

Unemployment_all

Unemployment_HI

Unemployment_LI

$\mathrm{CO}_{2}$ all

$\mathrm{CO}_{2}$ HI

$\mathrm{CO}_{2} \mathrm{LI}$
165

9

116

171

50

121

171

50

121

171

50

121

99

42

57

99

42

57

99

42

57

99

42

57

85

40

45

78

39

39

182

53

129

179

53

126

181

52

129
2.2521

2.1737

1.8153

0.2501

0.2648

0.2041

0.2548

0.2582

0.1909

0.1926

0.2158

0.1424

0.2741

63.9191

51.5952

73

39.4747

54.119

28.6842

47.6666

46.2381

48.7193

64.0202

66.0714

62.5087

41.7529

52.475

32.2222

48.2179

48.923

47.5128

59.3013

79.7533

50.8985

7.0124

5.6751

7.575

4.5439

10.3647

2.1975
1.08

1.92

1.08

0.023

0.023

0.071

0.012

0.04

0.012

0.016

0.019

0.016

9.87

9.87

8.22

0.9

0.9

0.889

0.858

0.858

0.816

0.77

0.776

0.636

\begin{tabular}{rrr}
20.8863 & 11 & 100 \\
22.7135 & 11 & 100 \\
13.7061 & 35 & 100 \\
22.0117 & 6 & 91 \\
22.2274 & 16 & 91 \\
14.3814 & 6 & 80 \\
18.7409 & 5 & 100 \\
22.8011 & 5 & 100 \\
15.2101 & 10 & 88 \\
21.4656 & 8 & 100 \\
23.1078 & 8 & 100 \\
20.2468 & 13 & 99 \\
22.8972 & 4 & 100 \\
22.1057 & 13 & 100 \\
19.2447 & 4 & 87 \\
22.9072 & 4 & 100 \\
19.8751 & 13 & 80 \\
25.8313 & 4 & 100 \\
22.8221 & 13.032 & 100 \\
14.7709 & 31.147 & 100 \\
20.0879 & 13.032 & 91.87 \\
5.2242 & 0.11 & 26.92 \\
3.3782 & 0.11 & 19.292 \\
5.7481 & 0.471 & 26.92 \\
6.1228 & 0.0447 & 43.8573 \\
8.2316 & 1.9842 & 43.8573 \\
2.5316 & 0.0447 & 14.3631 \\
\hline & &
\end{tabular}


Table 2: Correlation matrix

\begin{tabular}{|c|c|c|c|c|c|c|c|c|}
\hline & 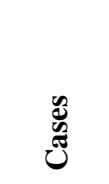 & : & $\begin{array}{l}\stackrel{n}{\sigma} \\
\stackrel{0}{\sigma}\end{array}$ & $\frac{\mathscr{c}}{\mathrm{S}}$ & 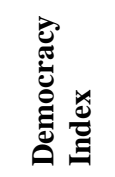 & 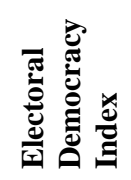 &  & 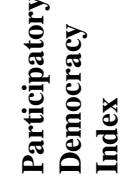 \\
\hline Cases & 1 & & & & & & & \\
\hline Deaths & 0.6231 & 1 & & & & & & \\
\hline Tests & 0.4254 & 0.3315 & 1 & & & & & \\
\hline $\begin{array}{l}\text { Case fatality } \\
\text { rate (CFR) } \\
\text { Democracy }\end{array}$ & 0.1317 & 0.7442 & 0.1287 & 1 & & & & \\
\hline $\begin{array}{l}\text { Index } \\
\text { Electoral } \\
\text { Democracy }\end{array}$ & 0.2066 & 0.3579 & 0.3523 & 0.302 & 1 & & & \\
\hline $\begin{array}{l}\text { Index } \\
\text { Liberal } \\
\text { Democracy }\end{array}$ & 0.2167 & 0.417 & 0.3481 & 0.358 & 0.897 & 1 & & \\
\hline $\begin{array}{l}\text { Index } \\
\text { Participatory } \\
\text { Democracy }\end{array}$ & 0.2479 & 0.4404 & 0.3946 & 0.372 & 0.9043 & 0.9754 & 1 & \\
\hline Index & 0.1755 & 0.4248 & 0.3152 & 0.385 & 0.8826 & 0.9672 & 0.9549 & 1 \\
\hline
\end{tabular}

Source: Authors' processings

\section{RESULTS}

\subsection{Main results}

First, to demonstrate the association between the vector of COVID-19 variables and various independent variables, we plot them against each other for our entire sample of worldwide countries (Figure 1). Figure 1 suggests a positive correlation between various measurements of democracy (Democracy Index - for exemplification) on the one hand and the COVID-19' spread for the total sample. However, when we conduct our analysis between the two groups, we may note different results, namely negative relationship for the high-income countries and positive relationship for the low-income countries, respectively. 
Figure 1: Scatter plots of democracy against COVID-19 spread the example of (COVID-19 Cases)

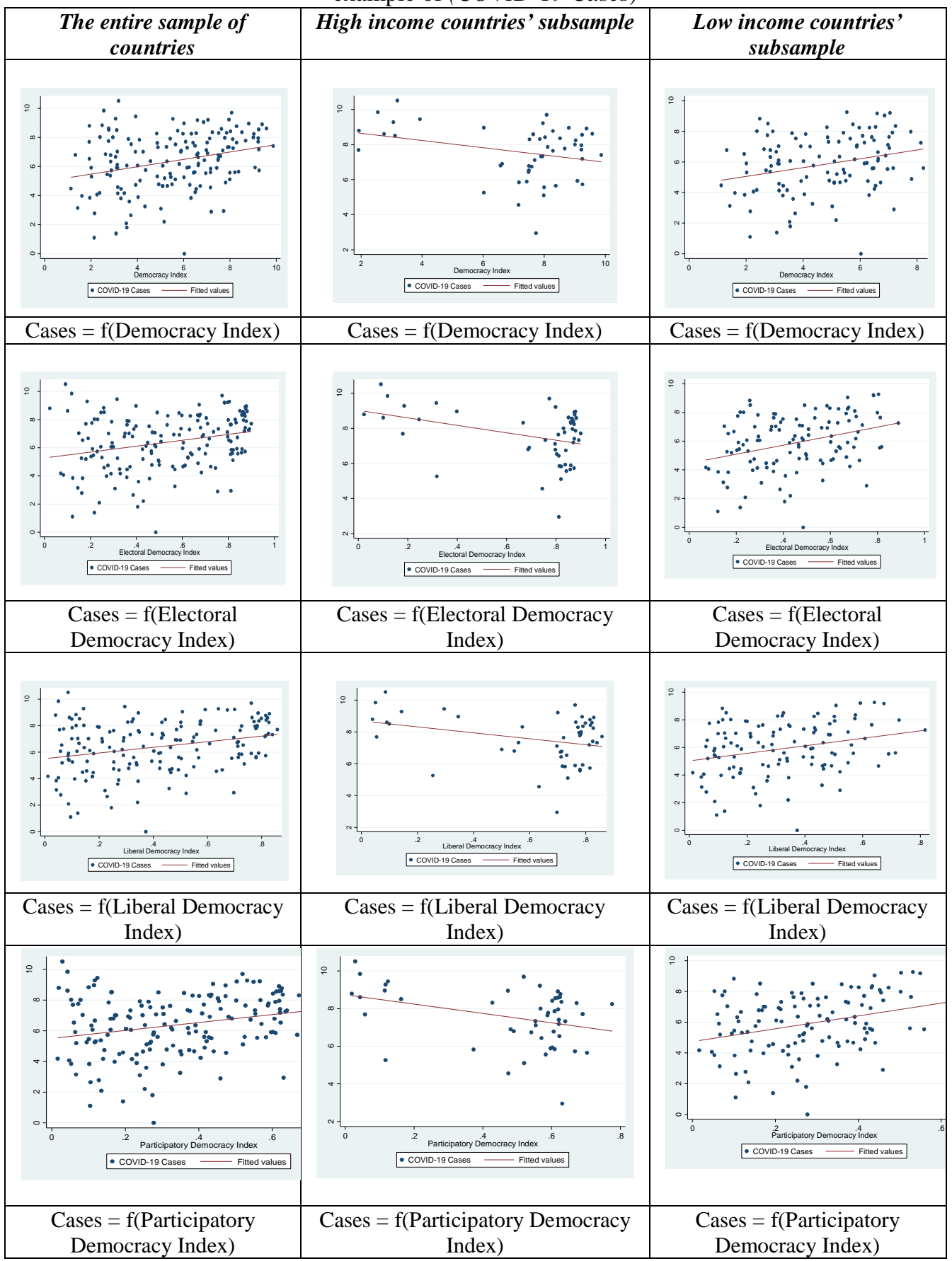


Our main results are found in Tables $3 a, 3 b, 3 c$ and $4 a, 4 b, 4 c$, reflecting the regression analysis between the spread of COVID-19 proxies (Cases, Deaths) on turn, and democracy, controlling for culture, urbanization, unemployment and pollution.

Table 3a uses LogCases as a proxy for the COVID-19 pandemic. The independent variables are Democracy (Democracy Index (Models (1), (1') and (1')), Electoral Democracy Index (Models (2), (2') and (2')), Liberal Democracy Index (Models (3), (3') and (3')) and Participatory Democracy Index (Models (4), (4') and (4'))). Table 3a contains simple log-linear regressions of LogCases as a function of the various democracy proxies (models (1), (2), (3), (4)), then the cultural significant dimensions are added and kept (models (1'), (2'), (3'), (4')), and the controls in the very last multiple regressions (models (1"), (2"), (3") and (4")). The natural logarithm of some variables is used for normality purposes.

In Table 3a, Democracy Index has a positive and significant coefficient of 0.2533 (model (1)). As Democracy Index increases, LogCases increases as well, with 0.2533 units, all other things equal. This Log-Linear regression basically shows that a 1-unit increase in Democracy Index corresponds to (approximately) an expected increase in Cases of $28.82 \%$. The amount of variance in LogCases explained by Democracy Index is of $7.65 \%$. Once the six cultural dimensions are added and the multiple regression is optimized through the backwards elimination technique, just the Uncertainty Avoidance UAI cultural dimension remains significant and positive, while the Adjusted $\mathrm{R}^{2}$ increases to $25.24 \%$ (model (1')). Model (1") controls for urbanization, unemployment and pollution, and urbanization has a positive and significant impact upon the number of COVID-19 cases.

Furthermore, when LogCases is estimated as a function of Electoral Democracy Index through model (2), the Electoral Democracy Index has a positive and significant coefficient of 2.1036, so the effect of a 1-unit increase in the Electoral Democracy Index is to multiply the expected value of Cases by 8.1956 , more than 8 times actually. When the cultural dimensions are added and the multiple regression is optimized through the backwards elimination technique, IND and UAI remain significant at various levels and positive, while the Adjusted $\mathrm{R}^{2}$ increases to $22.63 \%$ (model $(2 '))$. Model (2") adds controls and urbanization is positive and significant at a $5 \%$ level.

Models (3)-(3') deal with the estimation of LogCases as a function of the Liberal Democracy Index. The relationship between LogCases on the one hand and the Liberal Democracy Index on the other hand is direct, as the estimated coefficients for the Liberal Democracy Index are positive and significant at various levels. Out of the cultural dimensions, IND and UAI are significant (model (3')). Model (3”) supplementary validates a positive influence of urbanization.

In model (4), the interpretation of the 2.5905 estimated coefficient of Participatory Democracy Index is the change in LogCases for a one-unit change in the Participatory Democracy Index. In terms of Cases itself, this means that the expected value of Cases is multiplied by $13.33\left(\mathrm{e}^{2.5905}\right)$. The IDV and UAI cultural dimensions have a direct impact upon the number of COVID-19 Cases (model (4')) and so does urbanization (in model (4”)). 


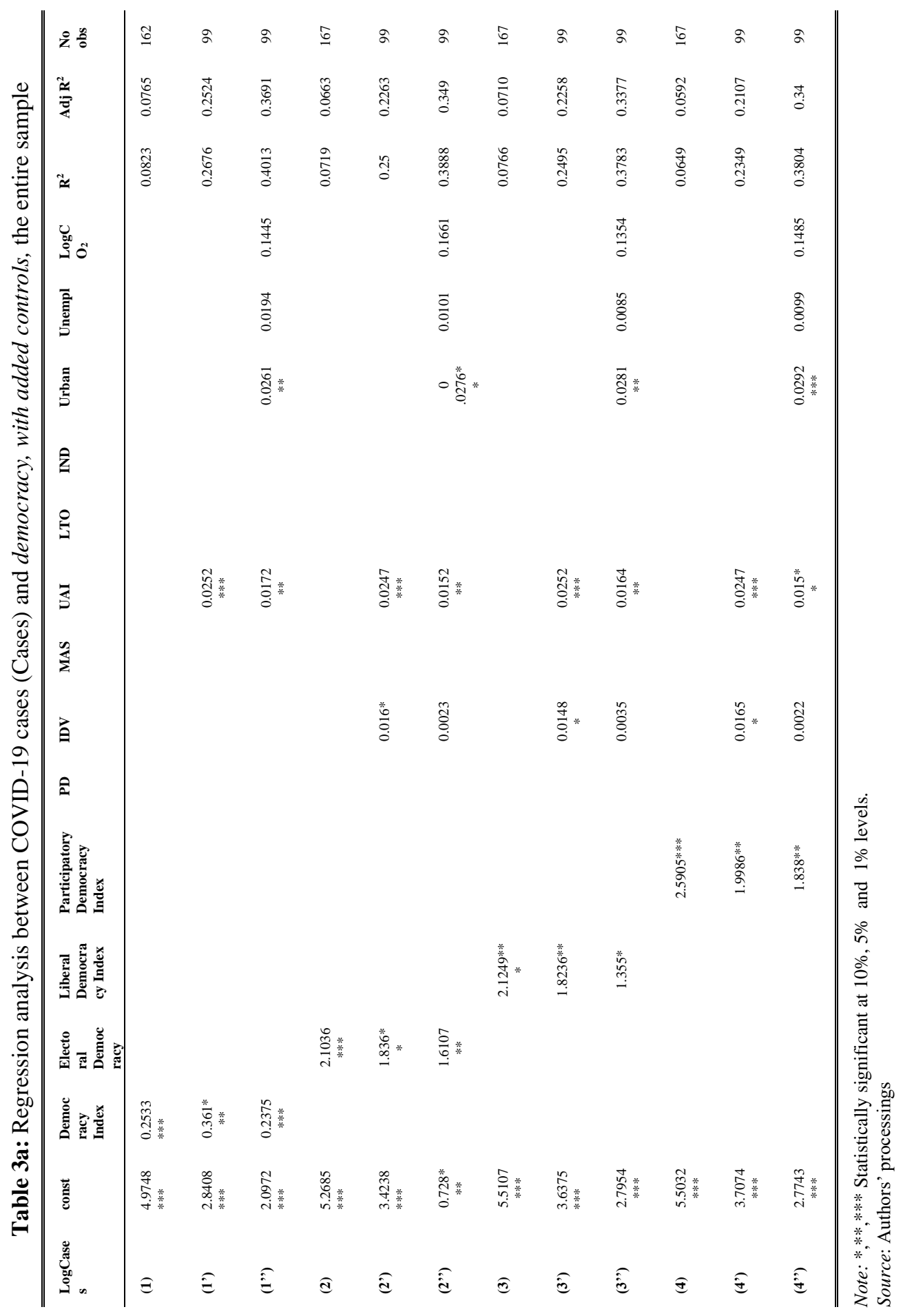









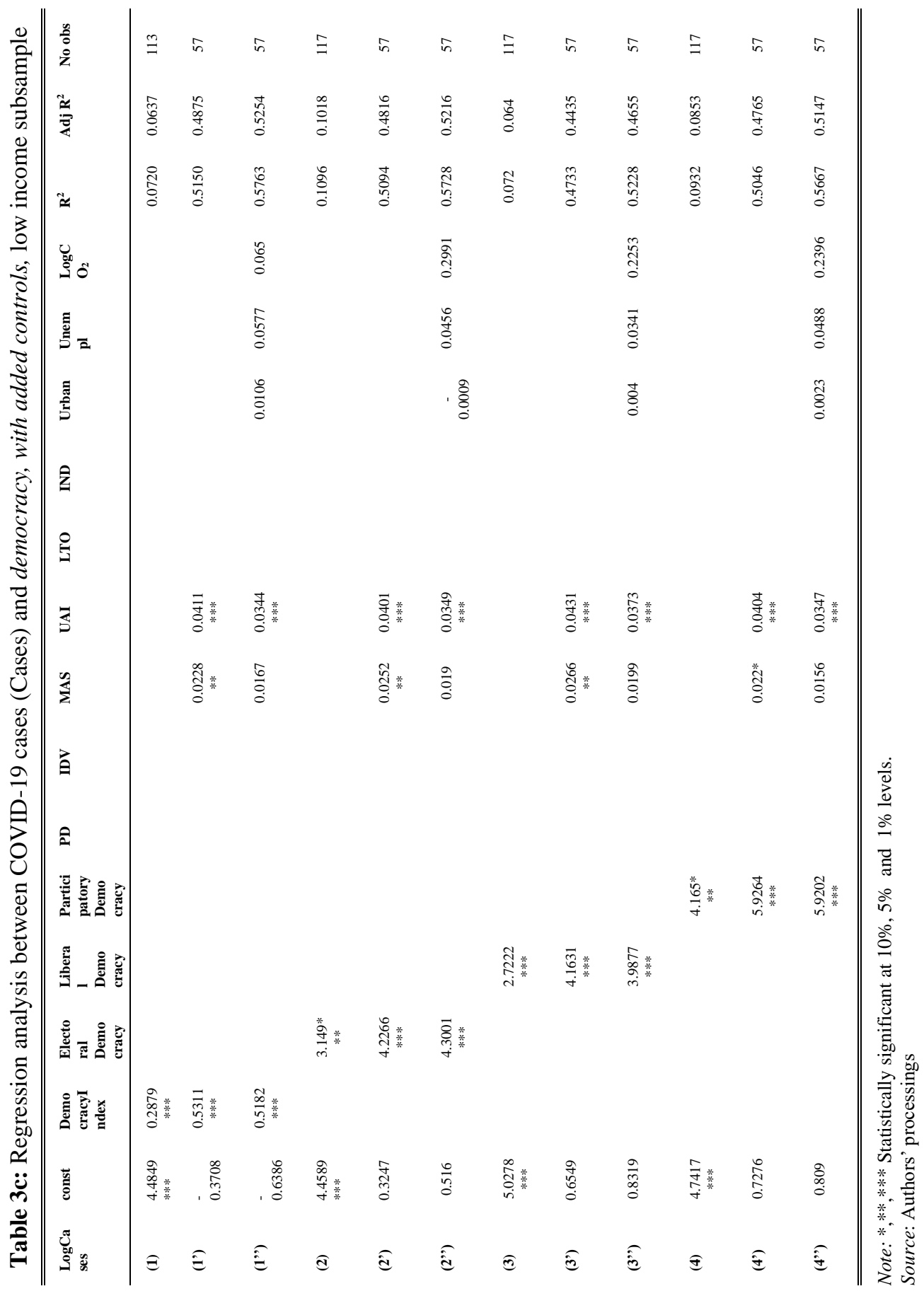


Tables $3 \mathrm{~b}$ and $3 \mathrm{c}$ estimate Eq 1 on subsamples of countries. The effect of democracy is striking, as the major difference between the two subsets of countries is the fact that for high income countries, regardless of which democracy index is used, its impact upon the number of COVID-19 cases is indirect: all the estimated coefficients for democracy proxies are negative and mostly significant throughout the entire Table 3b, models (1)-(4'). So, the higher the democracy within a developed country is, the lower its number of COVID-19 total cases. Then, for low income countries, Table $3 \mathrm{c}$ estimates positive and significant at $1 \%$ level coefficients for all the democracy indexes, in simple and extended regressions (Table 3c, models (1)-(4')). All these coefficients are higher than the ones from Table 3a.

Regarding the cultural dimensions, it seems that for high income countries, IDV and MAS are determinant for the number of COVID-19 Cases, when the four democracy proxies are used (Table $3 b)$. The positive impact of IND is validated in models (1') and ( $\left.1^{\prime \prime}\right)$. For low income countries, in Table 3c, MAS (models (1'), (2'), (3') and (4')) and UAI (models (1')-(1'), (2')-(2'), (3')-(3') and $\left.\left(4^{\prime}\right)-\left(4^{\prime \prime}\right)\right)$ have a direct influence upon the number of COVID-19 cases.

Table 4a estimates Log-linear models of the number of COVID-19 deaths as a function of democracy proxies (models (1), (2), (3) and (4)), further adding cultural dimensions (models (1'), (2'), (3') and (4')) and controlling for the social, economic and environmental dimensions mentioned above (models (1"), (2"), (3") and (4")), for the entire sample of 185 worldwide countries. Tables $4 \mathrm{~b}$ and $4 \mathrm{c}$ perform the same estimations but for the two subsamples of 54 high income countries and 131 low income countries respectively.

In Table 4a model (1), the interpretation of the 0.2774 estimated coefficients of Democracy Index is the change in LogDeaths for a one-unit change in Democracy Index and it is significant at a $1 \%$ level: a 1-unit increase in Democracy Index corresponds to (approximately) an expected increase in Deaths of $31.96 \%$. When the cultural dimensions are added and the model is optimized, IDV and UAI remain significant, having a positive influence upon the number of COVID-19 Deaths (model (1'), and also models (2'), (3') and (4')).

For the case of Electoral Democracy Index in model (2) we obtain that each one unit increase of Electoral Democracy Index increases LogDeaths by 2.5084 units, on average, everything else unchanged, representing that the expected value of Deaths would be multiplied by 12.28. For the cultural variables, the estimated coefficients of IDV and UAI are positive and significant at $1 \%$ level (model (2')).

The coefficient of Liberal Democracy Index is positive and significant in model (3) and it stays like that when the cultural dimensions and the controls are added (models (3')-(3")). Model (4) also provides a positive and significant coefficient for Participatory Democracy Index. Basically a 1 unit increase in the Participatory Democracy Index would increase the number of unlogged Deaths by 30.03 times on average, everything else unchanged (model (4)). So, increased democracies come with a multiplier effect of COVID-19 Deaths. 


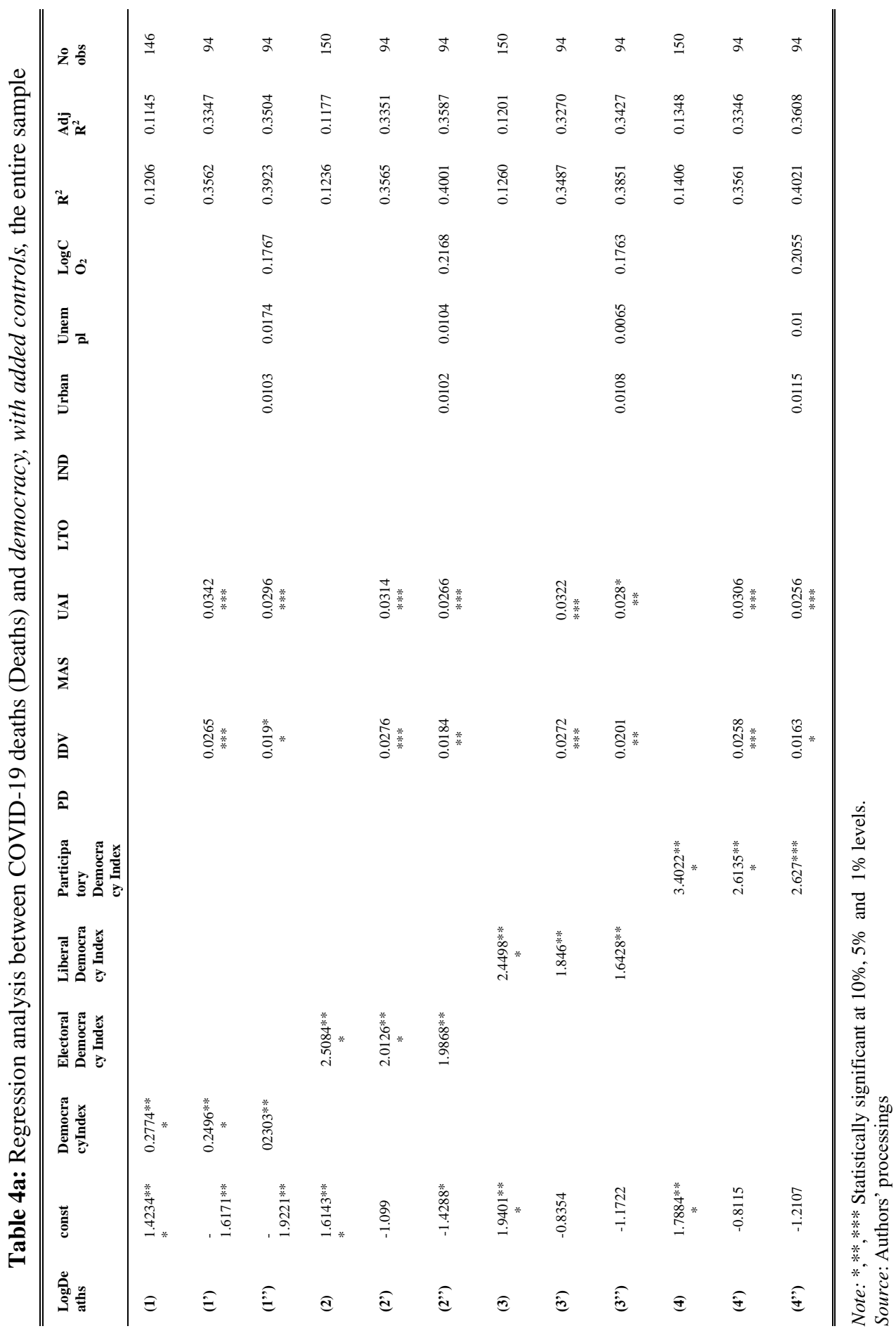




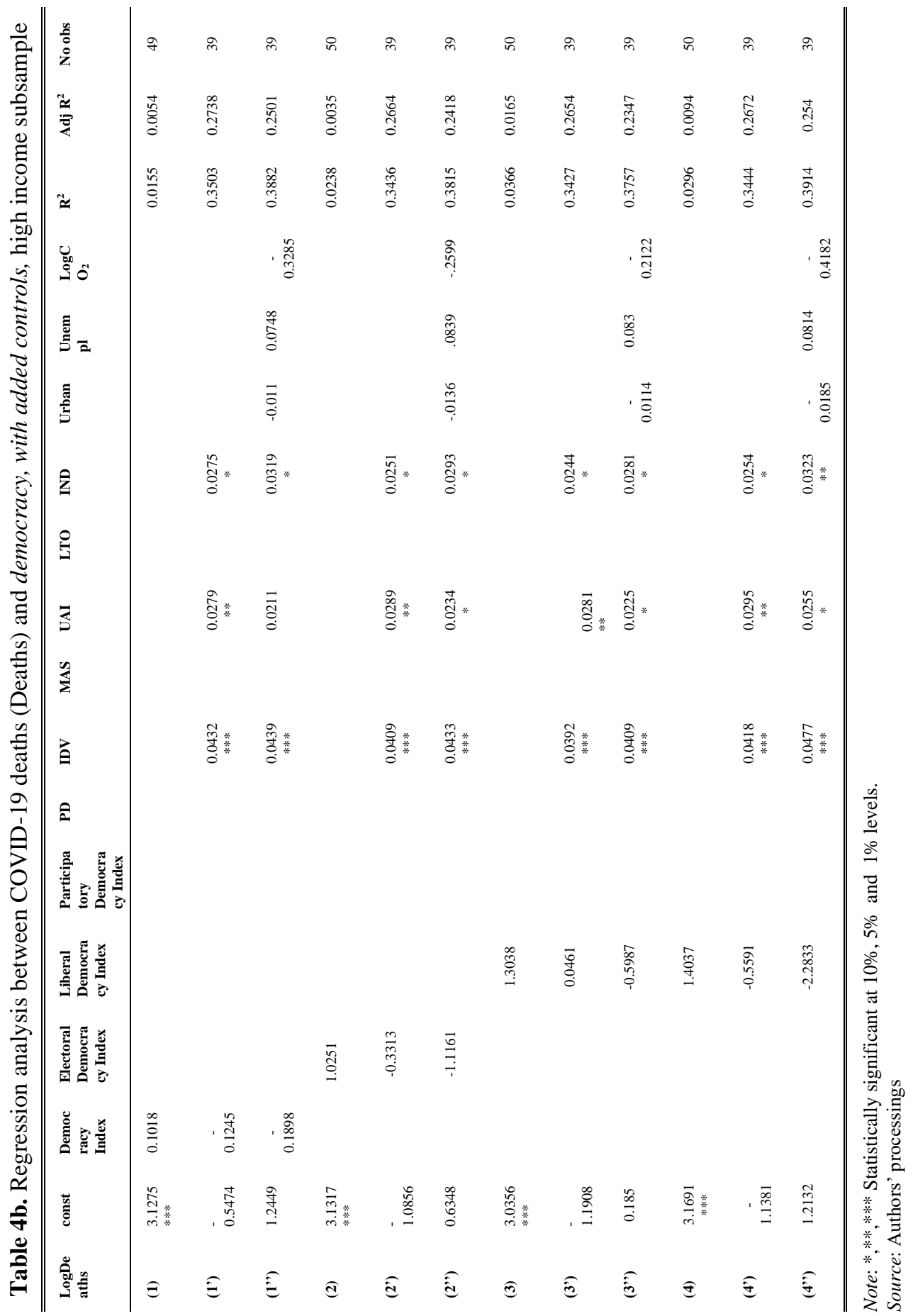







Tables $4 \mathrm{~b}$ and $4 \mathrm{c}$ estimate $\mathrm{Eq} 1$ on subsamples of high income and low income countries. Unfortunately, the estimated coefficients for the democracy proxies are not significant in Table 4b, for high income countries. Three cultural dimensions has a positive impact upon the number of COVID-19 deaths from high income countries: IDV, UAI and IND.

Then, for low income countries, Table 4c estimates positive and significant coefficients for all the democracy indexes, in simple and extended regressions (Table 4c, models (1)-(4'))). Comparing the values of these coefficients with the ones from Table 4a, we may notice that democracy brings a higher impact upon COVID-19 deaths in low income countries than for the entire mixed sample of countries. Regarding the cultural dimensions, it seems that for low income countries, UAI always has a direct impact upon the number of COVID-19 Deaths, when the four democracy proxies are used (Table 4b, models (1')-(1'), (2')-(2”), (3')-(3”) and (4')-(4”)). The positive impact of MAS in validated in models (1')-(1') and a mixed impact of IDV is also estimated (negative in models (2') and (4') and positive in models (3') and (3"). Model (2") supplementary validates a positive relationship between the number of COVID-19 Deaths and pollution, through Log-Log regression.

\subsection{Robustness checks}

The stability and reliability of our results has been checked by analysing the impact of democracy upon the COVID-19 spread controlling for culture, urbanization, unemployment and pollution, using the multiple regression modelling technique, on various axes, on turn: (1) we consider an alternative measure of our dependent variables, other proxies for the spread of the COVID-19 disease, i.e. the number of total tests for 1 million people Tests and the weight of Deaths within the Cases, also called Case Fatality Rate CFR, logged for normality reasons; (2) we consider alternative measures of our main independent variables, other two democracy proxies: the binary Democracy and Dictatorship and Polity, also used by Cheibub, Gandhi, and Vreeland (2010); and (3) we control for other effects by supplementing our regressions with some other control variables. Additional descriptions of these variables are included in our Appendix 1. Our main findings are mostly supported through these detailed robustness checks estimations, available on demand.

\section{DISCUSSIONS}

Both our main results and robustness checks confirm a strong influence between the level of democracy and the spread of COVID-19. When we analyse the entire sample we generally find a positive impact of democracy. However, different results for the two subgroups of countries are obtained when we conduct the analysis separately for each of the two subsamples of nations. Thus, we find a negative impact of democracy on the spread of COVID-19 in high income countries while a positive impact is found for low income countries. In other words, democracy influences the health outcomes of nations in terms of COVID-19's management because for the low income countries the effects of democracy are not as good as for the high income countries. Although these results are surprising, other similar findings come to support them. Thus, the study of Ross (2006) finds little evidence that the rise of democracy contributes to the fall in infant and child mortality rates for the poor countries. 
Even if democracy brings many political rights and liberties for the poor, these political rights produce few or no improvements for their actual material well-being (Ross, 2006). Regarding their financial situation, the study of United Nations found that $54.7 \%$ of respondents in Latin America would prefer a dictatorship instead of a democracy, if it would help "resolve" their economic problems (UNDP, 2004). This fact may explain why people in newly democratized countries often vote for candidates and parties associated with former dictators (Ross, 2006). The failure of democracies in the poor countries may be caused by the incomplete information received by the voters, the difficulty that politicians face in making credible promises, and social polarization (Keefer \& Khemani, 2003). Regarding polarization, Habyarimana et al. (2007) find that ethnic polarization in Africa tends to inhibit the provision of public services. In addition, it is obviously that democracies fund public services at a higher level than nondemocracies (Brown \& Hunter, 2004; Gerring et al., 2012; Kaufman \& Segura-Ubiergo, 2001) but there aren't clear evidences that these particular funds reach the poor and produce better social outcomes such as longer and healthier lives (Ross, 2006). The problem of corruption in healthcare occurs in the poor countries in order to get immediate financial benefits and thus it affects the efficiency of using funds within the healthcare system infrastructure. The study conducted by Achim et al. (2020) finds that corruption is significantly higher in low income countries than in high income countries. On the other hand, for the high income countries with traditional democracies a higher level of democracy has more chances to determine investments in proper healthcare infrastructures useful in the fight against the COVID-19 pandemic. Thus, in countries whose government is elected by the people, special care is given for getting a top management of the disease, compared to countries the dictatorships or communist regimes (the CFR, an indicator of COVID-19 management is analysed in Norrlöf (2020)). In the high income countries with improved quality of institutions, the public funds are efficiency used for providing higher level of public services compared to nondemocracies. Nonetheless, in Zimmermann et al. (2020) democracy is validated to have a positive influence upon the natural logarithm of CFR, just like the temperature and the weight of the population aged 65 and above within the total population.

In addition to these, we find that culture plays an important role in the spread of the COVID-19 disease due to the fact that it creates incentives for a behaviour favourable to accepting the rules imposed by the authorities in the fight against COVID-19. Our results are in line with those of Anderson, Heesterbeek et al. (2020) according to which "individual behaviour will be crucial to control the spread of COVID-19". More exactly, we find strong evidence that Individualism versus collectivism, Uncertainty avoidance and Masculinity vs. femininity are the most significant cultural dimensions in relation with the spread of COVID-19. First, for the entire sample of countries and also for the subsample of high income countries we find clear evidence that more individualistic societies are associated with higher levels of COVID-19 proxies and spread. People from individualistic cultures live their lives as they like, they are not constraint by the imposed rules of the group or the society. Individualist cultures are associated with emphases on independence, achievement, freedom and pleasure (Pentecostes, 1999), so the rules may be broken in order to achieve a certain independence. Our results are similar with the results of Achim et al. (2020), Pentecostes (1999) and Kawabata (2014) who also find that more collectivistic cultures increase the relationship between their members, determining a greater care towards one another, further having positive health outcomes. The collectivists are more prone to human solidarity, to a healthy lifestyle and therefore to a better physical health. Indeed, the study of Achim et al. (2020) finds that higher collectivism increases physical health (it reduces Life expectancy and increases the level of Mortality rate) and mental health as well (it reduces the level of Happiness). In addition, 
the studies conducted by Pentecostes (1999) and Kawabata (2014) find that the collectivism characterized by social trust and reciprocity is good for health promotion. This is because within a collectivist culture the interests of groups are above the personal interest, which is why they exclude people who do not conform to these societal expectations. Such collectivistic cultures allow the existence of individual foreigner goals for the purpose of promoting the healthy behaviour of the group and collective health is seen as outweighing the individual's loss of freedom (Pentecostes, 1999).

Regarding masculinity, we obtain evidence that it has a negative influence upon the spread of COVID-19 for high income countries and a positive influence for low income countries. We find that more masculine societies face lower levels of COVID-19's spread in high income countries, results that are similar to the ones obtained by Achim et al. (2020) for high income and more masculine countries. However, for the low income countries, we find opposite results: more feminine societies are associated with lower levels of COVID-19's spread. This happens because people from high income countries are already more feminine than people from low income countries (Table 2). Thus, people from high income countries require high masculinity (precise targets, heroism and achievement) to succeed in the fight against the current COVID-19 pandemic, while people from low income countries require more femininity (workplace flexibility and worklife balance may be important, a more care for the weak and quality of life). People from low income countries need to exchange more money and achievements for more care in their life and health while people from high income countries needs to exchange more flexibility in work and life for more precise targets and higher discipline.

Moreover, we find interesting but robust evidence that a higher level of uncertainty avoidance (a higher level of UAI) increases the spread of COVID-19. A high level of uncertainty avoidance reflects a high tendency to avoid the risks coming from ambiguous or unknown situations, thus reducing the extent of engaging in risky activities. The more the people avoid uncertainties, the more their fear of contacting the SARS-COV-2 virus has been replaced by their distrust within the authorities (WHO, Ministers, other public authorities) and fear of losing financial security. In these circumstances, people understand that it is more important to live, not just to be healthy, they become more scared of losing their jobs and their economic-financial security than of getting COVID-19, so they go out. Thus, an increase of uncertainty avoidance refers especially to an increase of the fear of losing one's job, financial independence and fear of losing a well-lived life, thus conducting to higher levels of COVID-19's spread. Our results use the data on July $11^{\text {th }}, 2020$, after the periods of lockdown had ended for all the world countries. In this moment, people have overcome their initial fears manifested in the middle of March and April. Fear and cultural differences have also been covered by the study of Jovančević and Milićević (2020).

Regarding the other control variables, we obtain positive and significant influences of urbanization, unemployment and pollution on the spread of the COVID-19 proxies. We find that an increase of urbanization (the percentage of total population living in urban areas) conducts to an increase of COVID-19's proxies, due to the low "social distance" which characterizes urban societies. Then, we find evidence that higher levels of unemployment determine a higher spread of COVID-19 because people are looking for ways to get out and avoid depression. Our results document that pollution also affects the spread of COVID-19, because pollution is mainly related to respiratory diseases (Yue et al., 2018) and increases the risk for pulmonary infections (Thomas \& Zelikoff, 1999). 


\section{CONCLUSIONS}

The central idea of this research paper springs as a result of clear evidence on how governments have understood to fight the pandemic and how they made their citizens aware of the application of several restrictive rules within countries. Therefore, our paper investigates the influence of democracy upon the spread of COVID-19 through the multiple regression technique on a sample of 185 worldwide countries (subsampled within high income and low income countries), also using many important control variables, such as culture, urbanization, unemployment and pollution.

We find clear evidence that high democracies correlate with the spread of COVID-19 but the results significantly differ between these two subgroups of countries. More exactly, in high income countries, higher levels of democracy reduce the spread of COVID-19 while in low income countries, the influence is exactly opposed. This result supports the finding that in poor countries democracy is not associated with a good management of COVID-19. Second, the cultural heritage of each nation also contributes to these results. Thus, we find clear evidence that culture has a significant influence on the spread of COVID-19. As such, a more individualistic society is associated with a larger spread of COVID-19. In addition, uncertainty avoidance and masculinity versus femininity highly influence the behaviour of nations in relation with the proxies of COVID19 for the analysed samples. Our finding has importance for the policy implications who need to understand why democracies perform so badly for their poorest people and what can be done to improve their record.

Our research is limited by the cross-sectional available data. The COVID-19 disease is an ongoing pandemic, so data are built up as the pandemic progresses. The after-math would only be quantified at its end, but there's still a long way to go, as World Health Organisation has recently warned. Econometric modelling techniques are limited to simple and multiple regression analysis of crosssectional data and some of the potential independent variables were strongly correlated, so they were omitted. These open the path towards other modelling techniques, such as cluster analysis of COVID-19 affected countries.

Nonetheless, another research avenue to be approached in the near future is that of testing other determinants of COVID-19 cases and especially deaths, strictly related to the life-style of nations: alcohol consumption, smoking incidence, body-mass indexes. As the pandemic progresses, nations have adapted and have increased their Intensive Care Unit (ICU) capacity. Plasma donations from recovered COVID-19 patients have also developed, in the absence of an authorised valid treatment or vaccine. Another interesting path to follow resides in the economic effects generated by the COVID-19: the decreased consumption of goods and services and the blockage or contractions of several economic sectors.

\section{AKNOWLEDGEMENT}

This work was supported by a grant of the Romanian Ministry of Education and Research, CNCS - UEFISCDI, project number PN-III-P4-ID-PCE-2020-2174, within PNCDI III. 


\section{REFERENCES}

Achim, M. V., Borlea, N. S., \& Văidean, V. L. (2020). Corruption and health outcomes within an economic and cultural framework The European Journal of Health Economics, 21, 195207.

Achim, M. V., Safta, I. L., Văidean, V. L., Muresan, G. M., \& Borlea, N. S. (2021). The impact of covid-19 on financial management: evidence from Romania. Economic Research Ekonomska Istraživanja. https://doi.org/10.1080/1331677X.2021.1922090

Afsahi, A., Beausoleil, E., Dean, R., Ercan S. A. \& Gagnon, J. P. (2020) Democracy in a Global Emergency Five Lessons from the COVID-19 Pandemic. Democratic Theory, 7(2), vxix. https://doi.org/10.3167/dt.2020.070201

Akerman, M., Moyses, S. T., Franco de Sá, R. M. P., Mendes, R., Nogueira, J. A. D., Zancan, L., Manoncourt, E., \& Wallerstein, N. (2019). Democracy and health promotion, Health Promotion International, 34(S1), March 2019, i1-i3. https://doi.org/10.1093/heapro/daz016

Albert, I., \& Trommsdorff, G. (2014). The role of culture in social development over the life span: an interpersonal relations approach. Online Readings in Psychology and Culture, 6(2), 130. https://doi.org/10.9707/2307-0919.1057

Allen, L. N., Nicholson, B. D., Yeung, B. Y. T., \& Goiana-da-Silva, F. (2020). Implementation of noncommunicable disease policies: a geopolitical analysis of 151 countries. Lancet Glob Health, 8, e50-58.

Anderson, R.M., Heesterbeek, H., Klinkenberg, D., \& Hollingsworth, T. D. (2020), How will country-based mitigation measures influence the course of the COVID-19 epidemic?, The Lancet, 395(10228), 931-934. https://doi.org/10.1016/S0140-6736(20)30567-5

Annaka, S., \& Higashijima, M. (2017). Democratization and Human Development. Winpec Working Paper Series No. E1712. Tokyo: Waseda Institute of Political Economy, Waseda University.

Ataguba, O. A., \& Ataguba, J. E. (2020), Social determinants of health: the role of effective communication in the COVID-19 pandemic in developing countries, Global Health Action, (13)1, 1788263. https://doi.org/10.1080/16549716.2020.1788263

Berengaut, A. A. (2020, February). Democracies Are Better at Fighting Outbreaks, The Atlantic. Retrieved from https://www.theatlantic.com/ideas/archive/2020/02/why-democraciesare-better-fighting-outbreaks/606976/

Breuer, C. (2015). Unemployment and Suicide Mortality: Evidence from Regional Panel Data in Europe. Health Economics, 24(8), 936-950.

Brown, D., \& Hunter, W. (2004). Democracy and Human Capital Formation. Comparative Political Studies, 37(7), 842- 864.

Bollyky, T. J., Templin, T., Cohen, M., Schoder, D., Dieleman, J. L., \& Wigley, S. (2019). The relationships between democratic experience, adult health, and cause-specific mortality in 170 countries between 1980 and 2016: an observational analysis. Lancet, 393, 16281640.

Cheibub, J. A., Gandhi, J., \& Vreeland, J. R. (2010). Democracy and Dictatorship Revisited. Public Choice, 143(2-1), 67-101.

Dutta, U. P., \& Gupta, H. (2019). ICT and health outcome nexus in 30 selected Asian countries: Fresh evidence from panel data analysis. Technology in Society, 59, 101184, 1-7.

Economist Intelligence Unit. (2019). Democracy index. Retrieved from https://www.eiu.com/topic/democracy-index 
Franco, A., Álvarez-Dardet, C., \& Ruiz, M. T. (2004). Effect of democracy on health: ecological study. BMJ, 329, 1421-1423.

Gaskell, J., \& Stoker, G. (2020) Centralized or Decentralized - Which Governance Systems are Having a "Good" Pandemic?, Democratic Theory, (7)2, 33-40. https://doi.org/10.3167/dt.2020.070205

Gerring, J., Thacker, S. C., \& Alfaro, R. (2012). Democracy and Human Development. The Journal of Politics, 74(1), 1-17.

Gettysburg Foundation. (2020). Democracy. Retrieved March 25, 2020 from https://www.gettysburgfoundation.org/gettysburg-revisited/democracy

Gondauri, D., \& Batiashvili M. (2020). The Study of the Effects of Mobility Trends on the Statistical Models of the COVID 19 Virus Spreading. Electronic Journal of General Medicine, 17(6), em243. https://doi.org/10.29333/ejgm/8212

Habyarimana, J., Humphreys, M., Posner, D. N., \& Weinstein, J. M. (2007). Why Does Ethnic Diversity Undermine Public Goods Provision?. American Political Science Review, 101(4), 709-725.

Hofstede, G. (2011). Dimensionalizing cultures: the Hofstede model in context. Online Read. Psychology and Culture, 2(1), 1-26. https://doi.org/10.9707/2307-0919.1014

Hofstede Insights. (2020). Compare countries. Retrieved May 10, 2020 from https://www.hofstede-insights.com/product/compare-countries/

Javidan, M., House, R. J., Dorfman, P. W., Hanges, P. J., \& De Luque, M. S. (2006). Conceptualizing and measuring cultures and their consequences: a comparative review of globe's and Hofstede's approaches. Journal of International Business Studies, 37(6), 897-914.

Jovančević, A., \& Milićević, N. (2020). Optimism-pessimism, conspiracy theories and general trust as factors contributing to COVID-19 related behavior - A cross-cultural study, Personality and Individual Differences, 167, 110216.

Justesen, M. K. (2012). Democracy, dictatorship, and disease: Political regimes and HIV/AIDS. European Journal of Political Economy, 28, 373-389.

Kaufman, R. R., \& Segura-Ubiergo, U. (2001). Globalization, Domestic Politics, and Social Spending in Latin America, World Politics, 53(4), 553-87.

Kavanagh, M. (2020). Authoritarianism, outbreaks, and information politics. The Lancet Public Health, 5(3), E135-E136. https://doi.org/10.1016/S2468-2667(20)30030-X

Kawabata, M. (2014). Is collectivism good for health promotion? Experiences of day labourers in Japan, Global Health Promotion, 20(4), 44-51. https://doi.org/10.1177/1757975913503384

Keefer, P., \& Khemani, S. (2003). Democracy, Public Expenditures and the Poor. World Bank Policy Research Working Paper No. 34.

Kudamatsu, M. (2012). Has democratization reduced infant mortality in sub-Saharan Africa? Journal of the European Economic Association, 10, 1294-1317.

Landrigan, P. J., Fuller, R., Hu, H., Caravanos, J., Cropper, M.L., Hanrahan, D., Sandilya, K., Chiles, T.C., Kumar, P., \& Suk, W. A. (2017). Pollution and Global Health - An Agenda for Prevention. Environmental Health Perspectives, 126(8), 084501-084506.

Liotti, G., Musella, M., \& D'Isanto. (2018). Does democracy improve human development? Evidence from former socialist countries. Eastern Journal of European Studies, 9(2), 6987.

Maiti, D., \& Awasthi, A. (2020). ICT Exposure and the Level of Wellbeing and Progress: A Cross Country Analysis. Social Indicators Research, 147, 311-343. 
Marshall, M. G., \& Gurr, T. R. (2020). Polity 5: Political Regime Characteristics and Transitions, 1800-2018 (Center for https://www.systemicpeace.org/inscr/p5manualv2018.pdf.

Miller, M. K. (2015). Electoral Authoritarianism and Human Development. Comparative Political Studies, 48(12), 1526-1562.

Mirza, N., Rahat, B., Nagvi, B., Kumail, S., \& Rizvi, A. (2020). Impact of Covid-19 on corporate solvency and possible policy responses in the EU. The Quarterly Review of Economics and Finance. https://doi.org/10.1016/j.qref.2020.09.002

Napier, A. D., Ancarno, C., Butler, B., Calabrese, J., Chater, A., \& Chatterjee, H. (2014). Culture and health. The Lancet Commissions, 384(9954), 1607-1639.

Norrlöf, C. (2020). Is covid-19 a liberal democratic curse? Risks for liberal international order. Cambridge Review of International Affairs, 33(5), 799-813. https://doi.org/10.1080/09557571.2020.1812529

Pentecostes, J. U. (1999). Individualism vs. collectivism: Implication for health promotion. Phillippine Journal Psychololgy, 32, 397-402.

Przeworski, A., Alvarez, M. E., Cheibub, J. A., \& Limongi, F. (2000). Democracy and Development: Political Institutions and Well-Being in the World, 1950-1990. Cambridge University Press.

Ramos, A. P. (2014). The Politics and the Measurement of Health Inequality in the Developing World. [Doctoral dissertation, University of California]. California Digital Library, 106128. https://escholarship.org/content/qt9d00t0b7/qt9d00t0b7.pdf

Rapeli, L., \& Saikkonen I. (2020). How Will the COVID-19 Pandemic Affect Democracy?, Democratic Theory, 7(2), 25-32. https://doi.org/10.3167/dt.2020.070204

Ross, M. (2006). Is Democracy Good for the Poor?. American Journal of Political Science, 50(4), 860-874.

Ruger, J. P. (2005). Democracy and health. QJM: An International Journal of Medicine, 98(4), 299-304.

Stearns, S. C., \& Slifkin, R. T., Edin, H. M. E. (2000). Access to Care for Rural Medicare Beneficiaries. The Journal of Rural Health, 16(1), 31-42.

Stroup, M. D. (2006). Economic Freedom, Democracy, and the Quality of Life. World Development, 35(1), 52-66.

Safaei, J. (2006). Is democracy good for health?. International Journal of Health Services, 36(4), $767-786$.

Tefft, N. (2011). Insights on unemployment, unemployment insurance, and mental health. Journal of Health Economics, 30, 258-264.

Thomas, P., \& Zelikoff, J. T. (1999). Air pollutants: Modulators of pulmonary host resistance against infection. In S. T. Holgate, J. M. Samet, \& R. L. Maynard, (Eds.), Air Pollution and health (pp. 357-379). Cambridge: Academic Press.

United Nations Development Programme (2004). Democracy in Latin America: Towards a Citizens' Democracy. New York.

V-Dem Institute. (2020). Varieties of Democracy (V-Dem) High-Level Democracy Indices, University of Gothenburg. https://www.V-dem.net/en/

Yue, M., Wang, S., Xie, J., M., P., \& Shang, K. (2018). Study about the impact of environmental conditions on respiratory diseases and prediction in Zunyi City. China Environmental Science, 38(11), 4334-4347. 
Wigley, S., Dieleman, J. L., Templin, T., Kiernan, S., \& Bollyky, T. K. (2020) Democracy and implementation of non-communicable disease policies. The Lancet Global Health, 8(4), $482-483$.

Wigley, S., \& Akkoyunlu-Wigley, A. (2017). The impact of democracy and media freedom on under-5 mortality. Social Science \& Medicine, 190, 237-246.

World Health Organization. (2020). How air pollution is destroying our health. https://www.who.int/airpollution/news-and-events/how-air-pollution-is-destroying-ourhealth.

World Bank Group. (2020). World Bank Data. Retrieved April 10, 2020 from http://www.worldbank.org

Worldometers. (2020). Worldometers. Retrieved April 10, 2020 from https://www.worldometers.info/coronavirus/

Zakaria, F. (1997). The Rise of Illiberal Democracies. Foreign Affairs, 76(6), 22-43.

Zimmermann, K. F., Karabulut, G., Bilgin, M. H., \& Doker, A. C. (2020). Inter-country distancing, globalisation and the coronavirus pandemic. World Economy, 43, 1484-1498. https://doi.org/10.1111/twec.12969

\section{APPENDICES}

Appendix 1: Description of variables

\begin{tabular}{|c|c|c|c|}
\hline Variables & Way of expressing & Units/scale & Sources \\
\hline \multicolumn{4}{|c|}{ Dependent variable } \\
\hline \multirow[t]{3}{*}{$\begin{array}{l}\text { COVID-19 } \\
\text { spread }\end{array}$} & $\begin{array}{l}\text { The confirmed number of COVID- } \\
19 \text { cases (Cases) }\end{array}$ & & $\begin{array}{lr}\begin{array}{l}\text { Worldometers } \\
\text { officially }\end{array} & \begin{array}{r}(2020), \\
\text { reported }\end{array}\end{array}$ \\
\hline & $\begin{array}{l}\text { The confirmed number of COVID- } \\
19 \text { deaths (Deaths) } \\
\text { The number of COVID-19 } \\
\text { performed tests (Tests) }\end{array}$ & $\begin{array}{l}\text { number/1 } \\
\text { million } \\
\text { population }\end{array}$ & $\begin{array}{l}\text { governmental data } \\
\text { www.worldometers.info/cor } \\
\text { onavirus/ }\end{array}$ \\
\hline & $\begin{array}{l}\text { Case Fatality Rate }(C F R) \text { - the } \\
\text { number of deaths divided by the } \\
\text { number of known infections (Lee } \\
\text { and Duchene, 2020). }\end{array}$ & $\%$ & $\begin{array}{l}\text { Authors' processings based } \\
\text { on Worldometers (2020) }\end{array}$ \\
\hline \multicolumn{4}{|c|}{ Independent variables } \\
\hline & $\begin{array}{l}\text { Democracy index is based on } 60 \\
\text { indicators grouped in five different } \\
\text { categories, measuring five } \\
\text { dimensions of democracy such as } \\
\text { Electoral process and pluralism, } \\
\text { Functioning of government, } \\
\text { Political participation, Political } \\
\text { culture, Civil liberties }\end{array}$ & $\begin{array}{c}\text { from } 1 \text { (very } \\
\text { low } \\
\text { democracy) to } \\
10 \text { (very high } \\
\text { democracy). }\end{array}$ & $\begin{array}{l}\text { The Economist Intelligence } \\
\text { Unit (2019) }\end{array}$ \\
\hline & $\begin{array}{l}\text { Electoral Democracy Index } \\
\text { Liberal Democracy Index }\end{array}$ & $\begin{array}{l}\text { Interval, from } \\
\text { low to high }\end{array}$ & $\begin{array}{l}\text { Varieties of Democracy (V- } \\
\text { Dem) High-Level }\end{array}$ \\
\hline Democracy & Participatory Democracy Index & $(0-1)$ & $\begin{array}{l}\text { Democracy Indices, } \\
\text { University of Gothenburg, } \\
\text { V-Dem Institute (2020) }\end{array}$ \\
\hline
\end{tabular}




\section{Control variables}

Culture

Urbanization

Unemployment

rate

Pollution
Democracy and Dictatorship

Polity

Power distance $(P D)$;

Individualism versus collectivism

$(I D V)$;

Masculinity versus femininity

$(M A S)$;

Uncertainty avoidance (UAI);

Long-term orientation (LTO);

Indulgence and restraint (IND).

Urban population (Urban) refers to people living in urban areas as defined by national statistical offices. The data are collected and smoothed by United Nations Population Division.

Total unemployment (modelled ILO estimate). Unemployment refers to the share of the labour force that is without work but available for and seeking employment.

$\mathrm{CO}_{2}$ emissions-Carbon dioxide emissions $\left(\mathrm{CO}_{2}\right)$ are those stemming from the burning of fossil fuels and the manufacture of cement. They include carbon dioxide produced during consumption of solid, liquid, and gas fuels and gas flaring.



From 0 points to 100 points for each of dimension

$\%$ of total

World Bank (2020) population

Percentage of total labour force

Hofstede Insights (2020)

World Bank (2020)

Metric tones

World Bank (2020) per capita

\section{Word Bank (2020)}


Developing Upper countries (Low middle income income countries) (131)
Lower

middle income

Low income (34)
Albania, Algeria, Angola, Argentina, Azerbaijan, Belarus, Belize, Bosnia and Herzegovina, Botswana, Brazil, Bulgaria, Colombia, Costa Rica, Cuba, Dominica, Dominican Republic, Ecuador, Gabon, Grenada, Hungary, Iran, Iraq, Jamaica, Jordan, Kazakhstan, Lebanon, Libya, Macedonia, Malaysia Maldives, Mauritius, Mexico, Montenegro, Namibia, Panama, Peru, Romania, Saint Lucia, Saint Vincent and the Grenadines, Serbia, Seychelles, South Africa, Suriname, Thailand, Tonga, Tunisia, Turkey, Turkmenistan, Venezuela.

Armenia, Bhutan, Bolivia, Cambodia, Cameroon, Cape Verde, Congo Republic, Côte d'Tvoire, Djibouti, Egypt, El Salvador, Georgia, Ghana, Guatemala, Guyana, Honduras, India, Indonesia, Kiribati, Kosovo, Kyrgyzstan, Laos, Lesotho, Mauritania, Moldova, Mongolia, Morocco, Nicaragua, Nigeria, Pakistan, Papua New Guinea, Paraguay, Philippines, Samoa, Sao Tome and Principe, Senegal, Sri Lanka, Sudan, Swaziland, Syria, Timor-Leste, Ukraine, Uzbekistan, Vanuatu, Vietnam, Yemen, Zambia.

Afghanistan, Bangladesh, Benin, Burkina Faso, Burundi, Central African Republic, Chad, Comoros, Congo Democratic Republic, Eritrea, Ethiopia, Haiti, Kenya, Korea (North), Gambia, Guinea, Guinea-Bissau, Liberia, Madagascar, Malawi, Mali, Mozambique, Myanmar, Nepal, Niger, Rwanda, Sierra Leone, Somalia, South Sudan, Tajikistan, Tanzania, Togo, Uganda, Zimbabwe.

*Note: We follow the classification made by World Bank (2020) in low-income countries (the low- and middle-income economies) and high-income countries (the high-income countries) 